\title{
Frameless Neuronavigation Assisted Brain Biopsy: Safety, Efficiency and Our Experience
}

\section{(i) Erdinç ÖZEK, id Hakan SEYITHANOĞLU, id Serkan KITTiş, io Tolga Turan DÜNDAR, id Abdurrahim TEKIN,}

(D) Mustafa Aziz HATIBBOĞLU

Bezmialem Vakıf University Faculty of Medicine, Department of Neurosurgery, İstanbul, Turkey

\begin{abstract}
Objective: Brain biopsy is a commonly used method for diagnosing deeply located or generalized intraparenchymal brain lesions and determining the further treatment options. A number of comparative studies have been performed with open surgical biopsy, framed or frameless biopsy methods. In this study, we shared the results of the framless neuronavigation assisted biopsy in our clinic and diagnostic sensitivity of this method.

Methods: Twenty-four cases of frameless neuronavigation assisted biopsy for cerebral intraparenchymal lesions between 2014 and 2016 were retrospectively reviewed. Seven cases had thalamic and 1 case had hypothalamic deep masses. Four cases had deeply located lesions on eloquent brain areas, 6 patients had diffuse lesions passing to the opposite cerebral hemisphere. Five cases had multiple cerebral masses and 1 case had exophytic mass originating from brainstem.

Results: Histopathologic diagnosis in 14 of 24 cases was grade IV glial tumor, diffuse grade III glial tumor in 1 and diffuse grade II glial tumor in 2. Histopathologic diagnosis of 5 cases were reported as B-cell lymphoma, whereas 1 case was reported as having gastrointestinal system metastasis. In one case, the diagnosis could not be made despite the biopsy was performed twice. The mitotic index (ki-67) showing tumor aggressiveness was $28.43 \%$ and range was $1-90 \%$. Twenty three of the 24 patients had a definite histopathological diagnosis and 1 patient had no histopathological diagnosis.
\end{abstract}

Conclusion: Frameless neuronavigation assisted brain biopsy is one of the most sensitive, safe and easy to perform stereotactic biopsy methods. The method which will be used with high accuracy and planning of biopsy require surgical experience.

Keywords: Biopsy, brain, neuronavigation

\section{Introduction}

In spite of current developments in radiological imaging techniques, accurate histological diagnosis is required to determine the appropriate treatment methods in intracranial lesions. Open surgical methods with mini-craniotomy and framed or frameless brain biopsies were used in diagnosis of intraparenchymal tumors. Neuronavigation devices are used in frameless brain biopsy. The advantages and disadvantages of framed or frameless brain biopsy techniques are still controversial; sampling accuracy, approach to deep brain lesions and sample volume are a few of controversial topics (1-10). In addition to this, there are discussions about the deficiencies of craniotomy with open biopsy and stereotactic biopsy techniques. In the literature, diagnostic accuracy was reported as 66-99\% in framed biopsy $(3-5,10,11)$, and as 89 $93 \%$ in frameless biopsy $(10-14) \%$, in the cases with frameless biopsy. In this respect, today, no method has been shown to have a definite superiority over another. It is obvious that the most

Address for Correspondence: Erdinç ÖZEK, Bezmialem Vakıf University Faculty of Medicine, Department of Neurosurgery, İstanbul, Turkey

Phone: +90 2124531700 E-mail: erdincozek@gmail.com ORCID ID: orcid.org/0000-0003-1860-4534

Cite this article as: Özek E, Seyithanoğlu H, Kitiş S, Dündar TT, Tekin A, Hatiboğlu MA. Frameless Neuronavigation Assisted Brain Biopsy: Safety, Efficiency and Our Experience. Bezmialem Science 2019;7(2):145-9. 
important criteria determining the accuracy of the diagnosis are patient selection and correct planning.

In this study, we shared our diagnostic accuracy and experience with our results of the patients who underwent biopsy with the help of neuronavigation for intraparenchymal lesions in our clinic.

\section{Methods}

Twenty-four cases of assisted biopsy with frameless neuronavigation (Stealth Station Treon ${ }^{\mathrm{TM}}$ Vertek $^{\odot}$, Medtronic, Minnesota, USA) for cerebral intraparenchymal lesions between November 2014 and December 2016 in our clinic were retrospectively investigated. The study was approved by the local ethics committee. Informed consent was taken from all patients. Of 24 patients, 15 were male and 9 were female. The mean age was 61 (38-84) years. Of the patients who had intraparenchymal masses, 7 had thalamic masses and 1 had hypothalamic mass. The masses of four cases were deeply located on eloquent brain areas. The masses of the six cases were widespread (diffuse) and spread to the opposite cerebral hemisphere. There were more than one cerebral mass in five cases, whereas there was an exophytic mass originating from the brainstem in one case (Table 1).

\section{Surgical Procedure}

Frameless biopsy using the Medtronic Stealth Treon ${ }^{\mathrm{Tm}}$ Vertek $^{\circ}$ (Stealth Station Treon ${ }^{\text {TM }}$ Vertek $^{\circ}$, Medtronic, Minnesota,USA) neuronavigation system was performed in all patients. Axial T2 constructive interference in steady state (CISS) and contrast enhancing axial T1 magnetic resonance (MR) slices with $1 \mathrm{~mm}$ thickness were taken and loaded to the neuronavigation device before surgery to determine the safest route (Figure 1). All patients

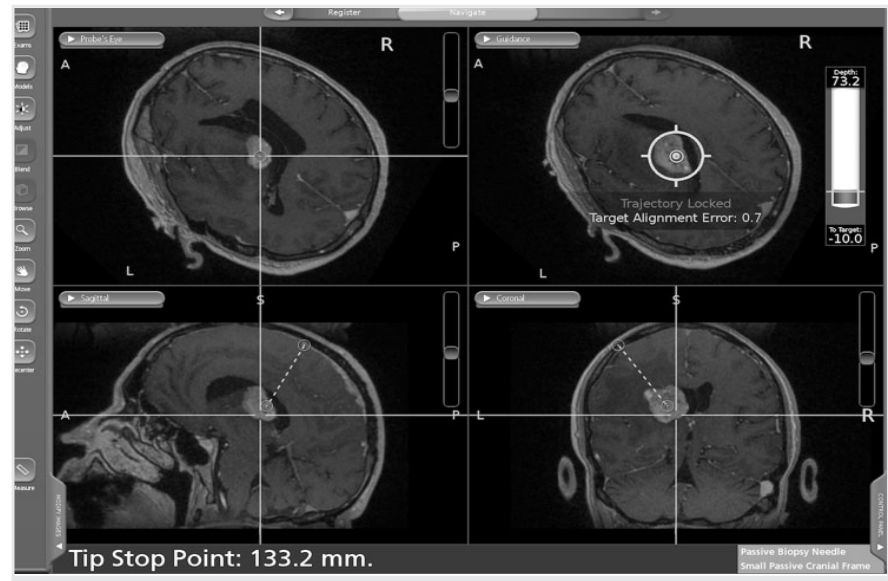

Figure 1. Planning of biopsy in neuronavigation device

Table 1. Features of the patients

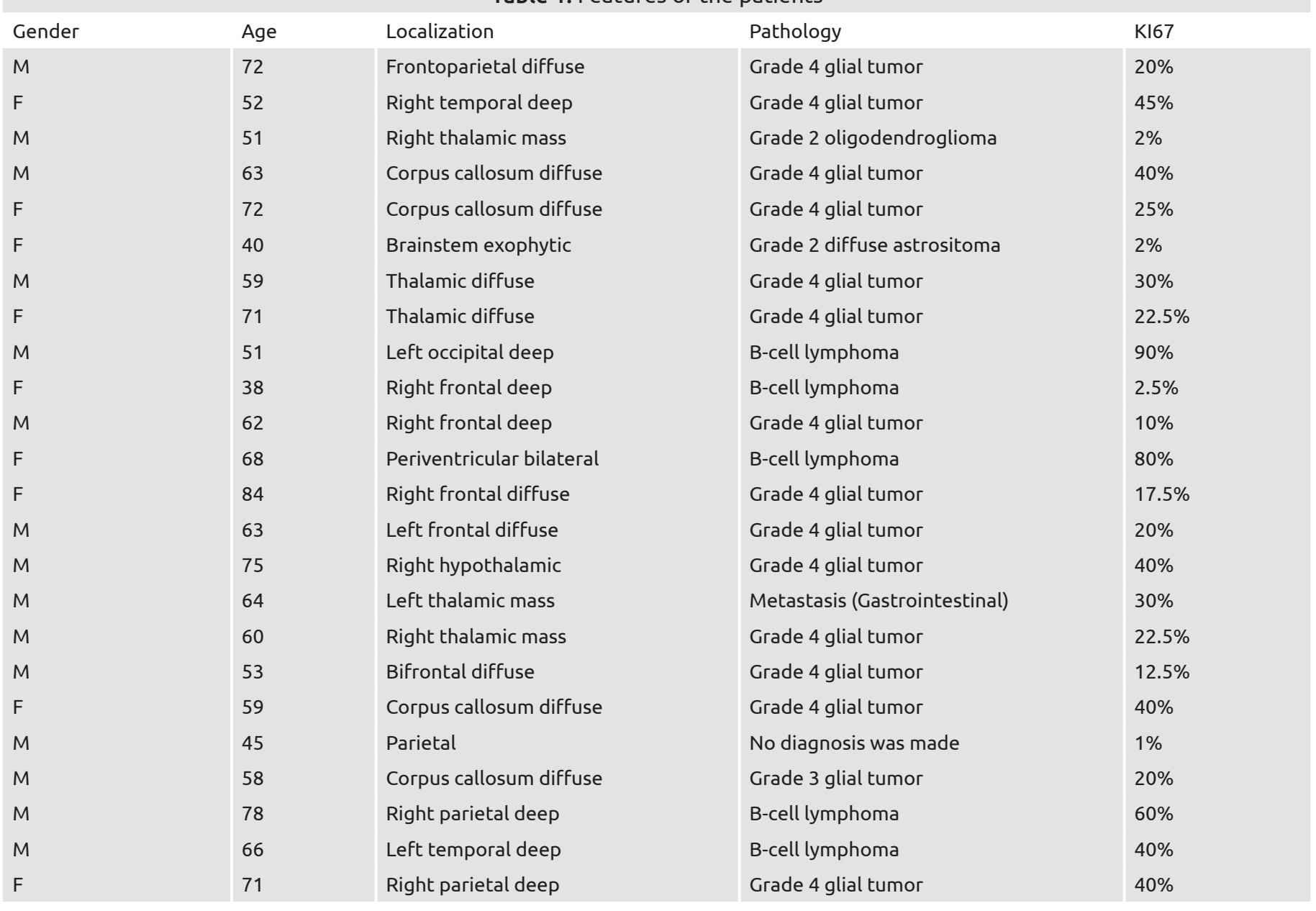


were fixated with 3-pin Mayfield head holder in an appropriate head position for biopsy plan under general anesthesia. The patients were recorded to the system using the neuronavigation system surface marking technique. With appropriate skin incision and $1 \mathrm{~cm}$ burr hole, the Stealth $\operatorname{Treon}^{\mathrm{TM}} \operatorname{Vertek}^{\circ}$ (Stealth Station $\operatorname{Treon}^{\mathrm{TM}}$ Vertek $^{\circ}$, Medtronic, Minnesota,USA) model neuronavigation instruments were used. Biopsies with $8 \mathrm{~mm}$ in length and $1 \mathrm{~mm}$ in thickness were taken in different depths and in all of 4 directions and were sent to the histopathology department for frozen biopsy during the operation. Permanent

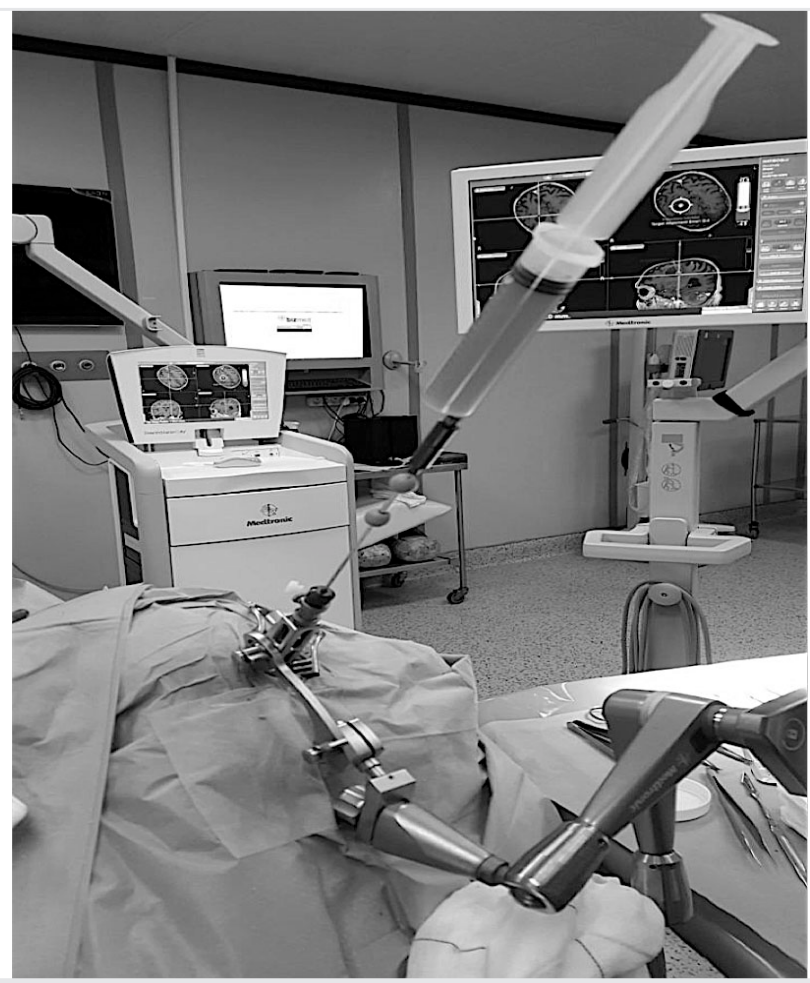

Figure 2. Sampling during surgery

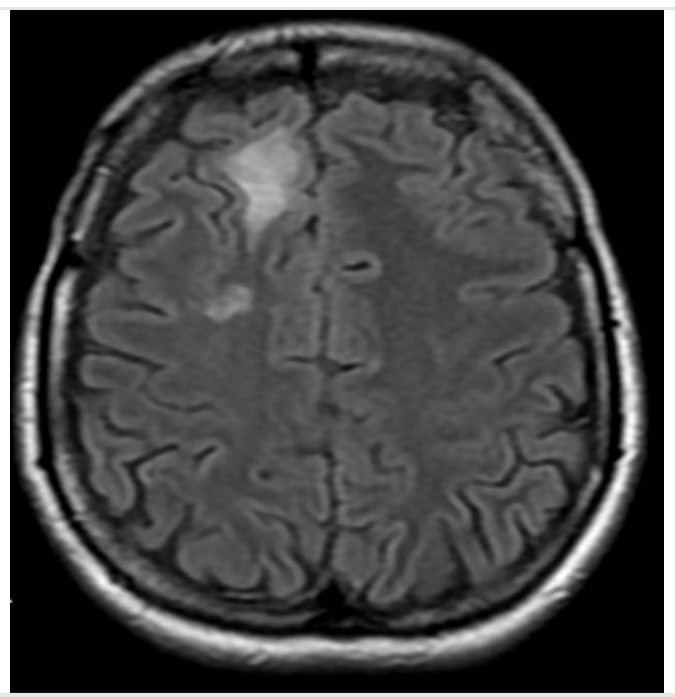

Figure 3. Pre-operative axial T1 weighted FLAIR magnetic resonance image pathological specimens were taken from the patients in whom tumor was detected in frozen biopsy and surgery was terminated (Figure 2).

\section{Complications and Mortality}

All patients underwent cranial CT after surgery for the risk of complication in the early period and were monitored for 1 day and followed up in surgical intensive care ünit. There were no early or late surgical complications, new neurological deficits or mortality due to surgery.

\section{Results}

The histopathological diagnosis of the patients who underwent biopsy due to cerebral intraparenchymal mass was reported as stage IV glial tumor in 14 patients, stage III glial tumor in 1 patient and stage II diffuse glial tumor in 2 patients. Histopathologic diagnosis of 5 cases were reported as B-cell lymphoma, whereas 1 case was reported as having gastrointestinal system metastasis. In one case, the diagnosis could not be made despite two biopsies performed with one month interval. The mitotic index (ki-67) showing tumor aggressiveness was $28.43 \%$ and range was $1-90 \%$. Twenty three of the 24 patients had a definite histopathological diagnosis and 1 patient had no histopathological diagnosis. Undiagnosed patient was first followed up as cortical dysplasia or low grade glioma. Then, progression in the right frontal subcortical lesion was observed in cranial MR and performing a biopsy was decided (Figures 3 and 4). Despite all histopathological and immunohistochemical studies for diagnosis, pathological diagnosis was not established and progression in the lesion was observed in follow-up (Figure 5). Second biopsy was performed but again definite histopathological diagnosis was not made. Open surgery was planned as a decision of the Council of neuro-oncology, but a decrease in lesion size was observed in cranial MRI performed in the late period (Figure 6). Surgical intervention was abandoned and follow-up was planned.

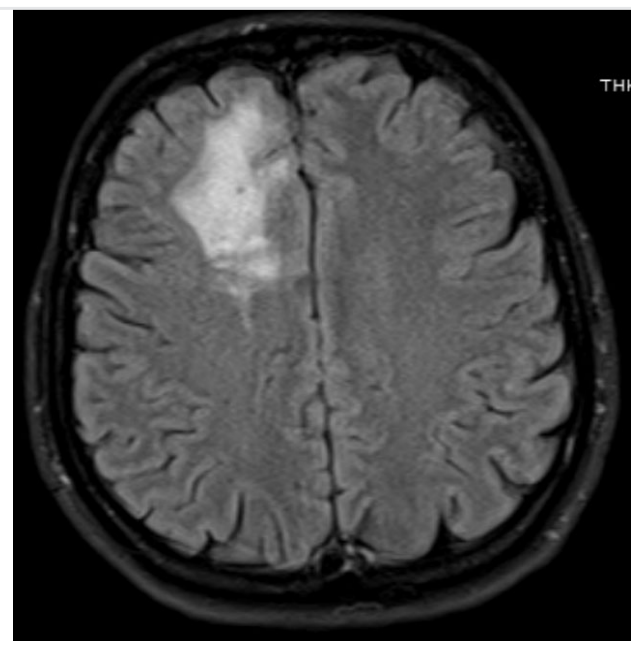

Figure 4. Progression in pre-operative axial T1 weighted FLAIR magnetic resonance image 


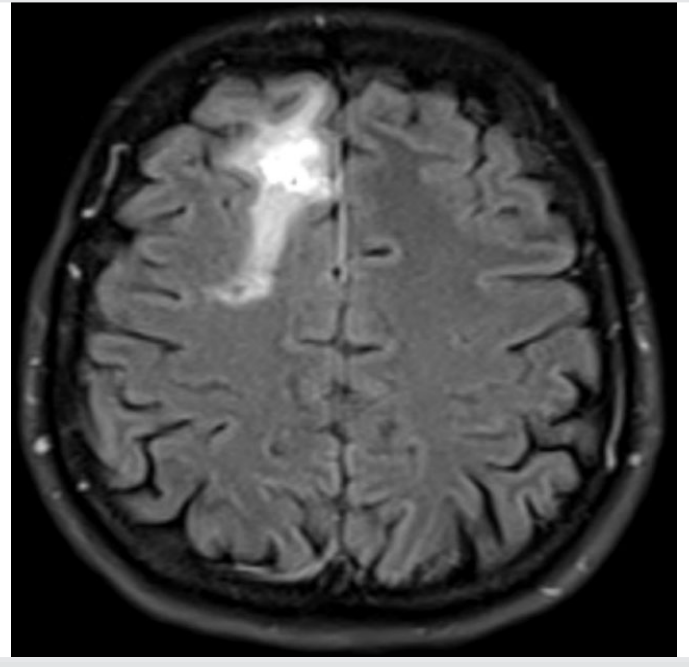

Figure 5. Axial T1 weighted FLAIR magnetic resonance image after biopsy

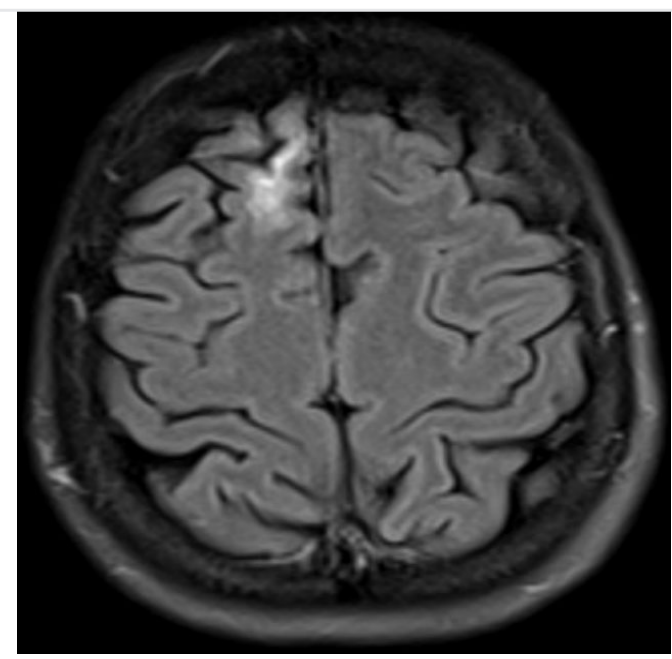

Figure 6. Spontaneous regression in the lesion after biopsy in the late period

\section{Discussion}

The main aim of all procedures of biopsy for cerebral intraparenchymal lesions including framed, frameless or open surgery with craniotomy is to be easy to use, to be reliable and to be able to diagnose correctly. Several studies have been conducted in the literature comparing stereotactic biopsy with or without frame and open biopsy based on diagnosis. In all these studies, a success rate of $51-79 \%$ was achieved especially in glioma staging and the causes for these low rates were shown as sampling error and low amount of tissue (10-14). With the advancement of technology, especially the number of frameless stereotactic biopsy devices are increasing and they are becoming widely used. In recent publications, there have been studies showing that the use of endoscope in addition to neuronavigation increases success in tissue diagnosis, however, larger series are needed because the number of cases is small (15). The reason of higher diagnostic sensitivity of framed stereotactic biopsy methods, is the excess number of cases in whom these methods are used for biopsy.
In our study, the diagnostic sensitivity of frameless stereotactic biopsy which is a new method was $95.8 \%$. In only one of the twenty-four cases, histopathological diagnosis was not made, although biopsy with neuronavigation was performed twice, but it was observed that the subcortical lesion was regressed spontaneously in the long-term follow-up. Frameless stereotactic biopsy was superior than framed stereotactic biopsy in terms of patient comfort and operation duration and had much more lower mortality and morbidity compared with open craniotomy and biopsy (16). In our study, no complication was observed in any of the 24 cases after surgery in the early and late period and no worsening of the neurological condition of the patients due to surgery was observed.

\section{Study Limitations}

Relatively low number of patients and short follow-up periods are the limitations of our study.

\section{Conclusion}

Frameless neuronavigation assisted brain biopsy is one of safe and easy-to-apply stereotactic biopsy methods with high diagnostic sensitivity. The method which will be used with high accuracy and planning of biopsy require surgical experience.

\section{Ethics}

Ethics Committee Approval: 08/146

Informed Concent: Informed consent was taken from the patients.

Peer Review: Externally peer-reviewed.

\section{Author Contributions}

Concept: E.Ö., Design E.Ö., Data Collection or Processing: E.Ö., Analysis or Interpreting: E.Ö., Literature Search: S.K., Writing: E.Ö.

Conflict of Interest: No conflict of interest was declared by the authors.

Financial Disclosure: The authors declared that this study received no financial support.

\section{References}

1. Amin DV, Lozanne K, Parry PV, Engh JA, Seelman K, Mintz A: Image-guided frameless stereotactic needle biopsy in awake patients without the use of rigid head fixation. J Neurosurg 2011 ;114:141420.

2. Chen CC, Hsu PW, Erich Wu TW, Lee ST, Chang CN, Wei KC, et al. Stereotactic brain biopsy: Single center retrospective analysis of complications. Clin Neurol Neurosurg 2009;111:835-9.

3. Dammers R, Haitsma IK, Schouten JW, Kros JM, Avezaat CJ, Vincent AJ. Safety and efficacy of frameless and frame-based intracranial biopsy techniques. Acta Neurochir (Wien) 2008;150:23-9.

4. Ferreira MP, Ferreira NP, Pereira Filho Ade A, Pereira Filho Gde A, Franciscatto AC. Stereotactic computed tomography-guided brain 
biopsy: diagnos- tic yield based on a series of 170 patients. Surg Neurol 2006;65 Suppl 1:S1:27-1:32.

5. Hall WA: The safety and efficacy of stereotactic biopsy for intracranial lesions. Cancer 1998;82:1749-55.

6. Kim JE, Kim DG, Paek SH, Jung HW. Stereotactic biopsy for intracranial lesions: reliability and its im- pact on the planning of treatment. Acta Neurochir (Wien) 2003;145:547-54.

7. McGirt MJ, Woodworth GF, Coon AL, Frazier JM, Amundson E, Garonzik I, et al. Independent predictors of morbidity after imageguid- ed stereotactic brain biopsy: a risk assessment of 270 cases. J Neurosurg 2005;102:897-901.

8. Shastri-Hurst N, Tsegaye M, Robson DK, Lowe JS, Macarthur DC: Stereotactic brain biopsy: an audit of sampling reliability in a clinical case series. Br J Neu- rosurg 2006;20:222-6.

9. Smith JS, Quinã ones-Hinojosa A, Barbaro NM, McDermott MW. Frame-based stereotactic biopsy remains an important diagnostic tool with distinct advantages over frameless stereotactic biopsy. J Neuro Oncol 2005;73:173-9.

10. Woodworth G, McGirt MJ, Samdani A, Garonzik I, Olivi A, Weingart JD. Accuracy of frameless and frame-based image-guided stereotactic brain biopsy in the diagnosis of glioma: comparison of biopsy and open resection specimen. Neurol Res 2005;27:358-62.
11. Shooman D, Belli A, Grundy PL: Image-guided frameless stereotactic biopsy without intraoperative neuropathological examination. J Neurosurg 2010;113:170-8.

12. Chandrasoma PT, Smith MM, Apuzzo ML. Stereo- tactic biopsy in the diagnosis of brain masses: com- parison of results of biopsy and resected surgical specimen. Neurosurgery 1989;24:160-5.

13. Jackson RJ, Fuller GN, Abi-Said D, Lang FF, Gokaslan ZL, Shi WM, et al. Limitations of stereotactic biopsy in the initial management of gliomas. Neuro Oncol 2001;3:193-200.

14. McGirt MJ, Villavicencio AT, Bulsara KR, Friedman AH. MRIguided stereotactic biopsy in the diagnosis of glioma: Comparison of biopsy and surgical resec- tion specimen. Surg Neurol 2003;59:27782.

15. Tsuda K, Ishikawa E, Zaboronok A, Nakai K, Yamamoto T, Sakamoto N. Navigation-Guided Endoscopic Biopsy for Intraparenchymal Brain Tumor. Neurol Med Chir (Tokyo) 2011;51:694-700.

16. Verploegh SCI, Volovici V, Haitsma KI, Schouten WJ, Dirven MC, Kros MJ. Contemporary frameless intracranial biopsy techniques: Might variation in safety and efficacy be expected?. Acta Neurochir 2015;157:2011-6. 